\title{
Towards Real Time Diagnostics of Hybrid Welding Laser/GMAW
}

\section{0th Annual Review of Progress in Quantitative Nondestructive Evaluation}

\author{
T. R. McJunkin \\ D. C. Kunerth \\ C. I. Nichol \\ E. Todorov \\ S. Levesque
}

July 2013
The INL is a

U.S. Department of Energy

National Laboratory

operated by

Battelle Energy Alliance

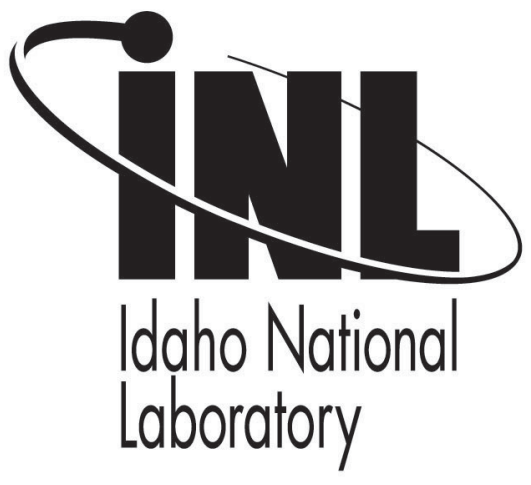

This is a preprint of a paper intended for publication in a journal or proceedings. Since changes may be made before publication, this preprint should not be cited or reproduced without permission of the author. This document was prepared as an account of work sponsored by an agency of the United States Government. Neither the United States Government nor any agency thereof, or any of their employees, makes any warranty, expressed or implied, or assumes any legal liability or responsibility for any third party's use, or the results of such use, of any information, apparatus, product or process disclosed in this report, or represents that its use by such third party would not infringe privately owned rights. The views expressed in this paper are not necessarily those of the United States Government or the sponsoring agency. 


\title{
Towards Real Time Diagnostics of Hybrid Welding Laser/GMAW
}

\author{
T.R. McJunkin ${ }^{\mathrm{a}}$, D.C. Kunerth ${ }^{\mathrm{a}}$, C.I. Nichol ${ }^{\mathrm{a}}$, E. Todorov ${ }^{\mathrm{b}}$, and S. Levesque ${ }^{\mathrm{b}}$ \\ ${ }^{a}$ Idaho National Laboratory, Idaho Falls, ID 83415-3570 \\ ${ }^{b}$ Edison Welding Institute, Columbus, $\mathrm{OH}$
}

\begin{abstract}
Methods are currently being developed towards a more robust system real time feedback in the high throughput process combining laser welding with gas metal arc welding. A combination of ultrasonic, eddy current, electronic monitoring, and visual techniques are being applied to the welding process. Initial simulation and bench top evaluation of proposed real time techniques on weld samples are presented along with the concepts to apply the techniques concurrently to the weld process. Consideration for the eventual code acceptance of the methods and system are also being researched as a component of this project. The goal is to detect defects or precursors to defects and correct when possible during the weld process.
\end{abstract}

Keywords: Ultrasonic, Eddy Current, Hybrid Laser Welding, Diagnostic, Control, Advanced Manufacturing PACS: 81.05, 52.77.Fv, 81.70.Ex, 81.70

\section{INTRODUCTION}

Development and improvement of advanced manufacturing methods for nuclear energy and other fabrication is an important topic as a means to ensure safety and improve cost structure in constructing new facilities. One area of interest is high throughput welding accomplished with laser and hybrid/laser processes. There are many benefits to these joining methods including decreased heat input, achieving less disruption to microstructure of the weld. However, there are downsides in that if the process has an issue a large volume of bad weld can be produced. The welder operating the system may not recognize some flaws or precursors to flaws, so a system can be put in place to assist the welder in monitoring. To those ends, this paper focuses on sensors that can directly find indications of flaws that are not available visually. The two methods addressed are eddy current sensor (Edison Welding Institute) that is in the modeling phase of design and tandem phased array method (INL) for monitoring the vertical root face that may be susceptible to lack of fusion defect that is not visible in process.

There are two major types of flaws that may be present in the hybrid laser gas metal arc welding (HLGMAW) joints - planar and volumetric or pores [1]. The planar flaws are hot cracks along the center line (CL), lack of fusion (LOF) or missed seam, and lack of penetration (LOP) at the root. Pores could have various shapes or sizes from very small, less than $1 \mathrm{~mm}$ up to $2 \mathrm{~mm}$ throughout the volume. Although the flaw size, location and distribution are indicative of the weld quality process during fabrication, the planar flaws with critical sizes will affect significantly the joint fatigue performance in service.

Conventional nondestructive evaluation (NDE) techniques such as radiography (RT), ultrasonics (UT), magnetic particle (MT), liquid penetrant (PT) and visual testing (VT) are usually used to examine the weld joints [1, 2]. The MT, PT and VT will not detect critical slightly subsurface or volumetric flaws. Tight planar flaws are also difficult to detect with RT [2]. Eddy current (ET) has been recommended [2] for examination of HLGMAW joints. The array eddy current (AEC) has proven to be very effective and fast for examination of laser welds [3]. One advantage of the ET that makes it specifically attractive for real or near-real time weld monitoring is the ability of the electromagnetic and eddy current techniques to inspect the weld without direct mechanical contact with the surface.

The objective of this study is to design, build and demonstrate an ET sensor and technique for weld process monitoring. The objective of the first phase of the project was to investigate virtually and optimize the ET sensor performance in detection of surface and subsurface flaws after the first and second passes of the HLGMAW. 
The objective of the phased array UT approach is to detect flaws in the volume of the weld. The nature of the laser process enables it, with a large enough laser, to penetrate up to an inch of vertical weld. Given this, a pitch catch approach for direct specular reflection detection of a lack of fusion or lack of penetration flaw is developed and validated under bench top conditions.

\section{APPROACH}

A laboratory hybrid laser welding system has been constructed to perform experimental welds for development of real time monitoring of the weld with sensors and techniques developed for the diagnostics. This section is segmented into three subsections describing the welding system, an ET sensor currently in the modeling phase, and the phased array ultrasonic techniques currently employed post weld. As the system develops further these components will be brought together for concurrent operation of the components.

\section{Weld/Material Configuration}

The welding system is made up of a computer controlled and monitored gas metal arc welder (GMAW). The computer also controls the gate of the laser, which is a continuous mode YAG fiber laser with maximum power of $4 \mathrm{~kW}$. The welding system is shown in FIGURE 1.

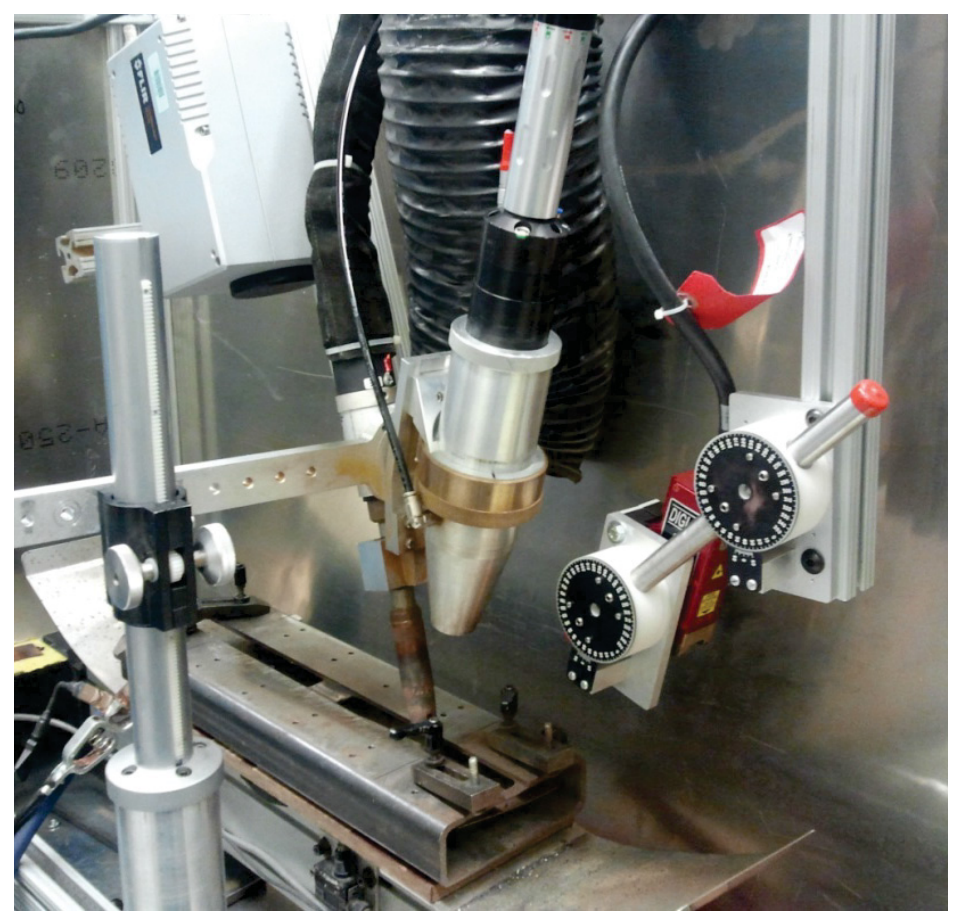

FIGURE 1. Welding system with FLIR camera, GMAW torch, welding laser, and laser profilometer.

The material chosen for this work is $316 \mathrm{~L}$ stainless steel. $316 \mathrm{~L}$ is a nuclear energy relevant material and has non-magnetic characteristics preferred for initial ET modeling and probe development. The current joint design is a J-groove steep wall joint with a $3.18 \mathrm{~mm}(0.125$-in.) vertical root face in a plate with total thickness of $9.53 \mathrm{~mm}$ (0.375-in.) The weld macros shown on the right of FIGURE 2, show a finished root and fill weld of the current joint design.

The power of the laser limits the thickness of the root face that can be penetrated. For the root pass welds of up to $25 \mathrm{~mm} / \mathrm{s}$ have been performed using a linear translation stage to move the part. FIGURE 2, shows a set of experimental runs with variable travel speeds and laser power. This weld was part of experiments to identify 
nominally successful welding parameters that had sufficient speed to avoid the problem of gravity pulling the weld pool through the laser keyhole through the root. Weld A shows the lack of penetration without laser enabled. Weld B illustrates welds that had a degree of weld pool drain. Welds D and E bound parameters that achieve penetration of laser and good GMAW weld bead characteristics (i.e. workmanship). The included right angle $\mathrm{V}$ groove yielded poor results at weld speeds above $20 \mathrm{~mm} / \mathrm{s}$. Based on this weld, the decision was made to move to a J-groove weld preparation shown on the right side of FIGURE 2.

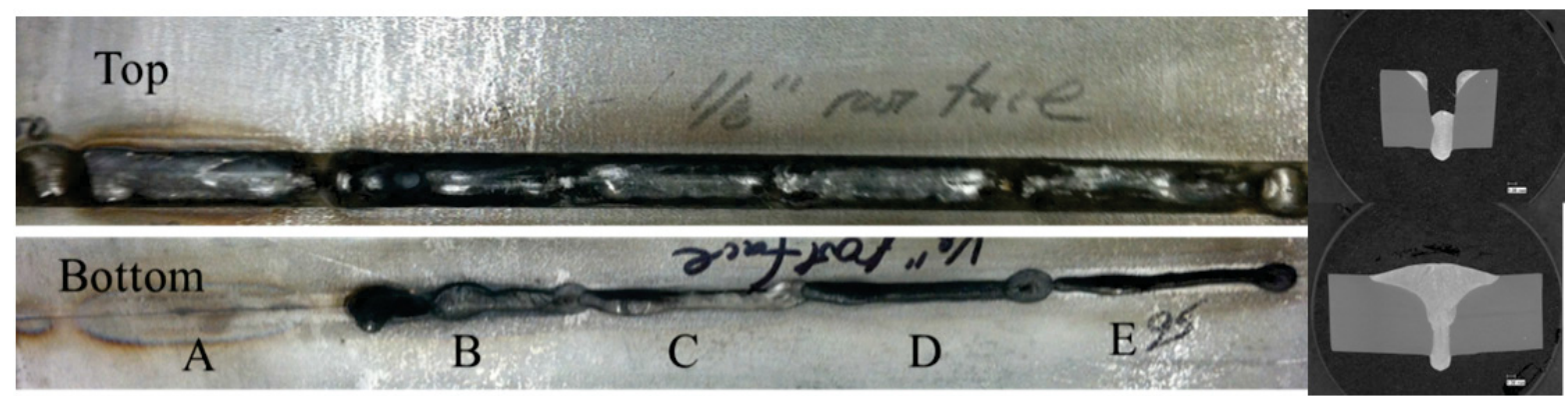

FIGURE 2. Sample one pass welds of a $9.53 \mathrm{~mm}(0.375$-in.) thick stainless plate. Each pass was made with different laser or travel speed parameters. To the right are macros of another weld showing the result of a root weld (top) and a second fill pass welded over the root weld.

A thermal imaging camera is set up to report weld and surface temperatures of the in progress weld. This information is used to form ball park design requirements for the probe. The localized heating from the laser and minimized heat input from the GMAW produces relatively cool surfaces in immediate proximity to the weld bead.

\section{Eddy Current Modeling (EWI)}

Two and three dimensional finite element models (FEM) were built to simulate the interaction between the sensor and the weld and optimize the sensor performance in flaw detection. The modeling was performed in the following sequence:

- Model the interaction of existing sensors with known and reproducible flaws and generate reference signals

- Optimize depth of penetration by selecting adequate transmitter and frequency

- Investigate the magnetic field disturbance from surface and subsurface flaws for selected transmitterreceiver configurations and frequencies

- Interact the selected sensor configurations with typical weld flaws and compare the flaw signals to the reference signals to determine the flaw detectability

\section{Root Face: Phased Array Ultrasonics (INL)}

A direct approach for detecting LOF in the root face of a laser weld uses the flexibility of linear phased array probes and systems. In the vertical portion of the weld that is fused with the laser heat, there is a potential for producing LOF even in a weld that shows full penetration. FIGURE 3 demonstrates a set of focal laws that produce a round trip from a send aperture with delays focusing on a point on the fusion surface, and a receive aperture focused on the same spot but on the reflected path with a bounce off the bottom surface of the plate[4]. Enough points are selected along the fusion surface to create the set of focal laws to maintain a fast repeat rate but not leave portions uncovered.Focal laws are calculated using a custom calculator designed to provide LAW files for input into Olympus NDT Tomoview. Hardware included, Olympus NDT FocusLT hardware, 5-MHz 64 element linear array, and a nominal $45^{\circ}$ shear wave wedge. 


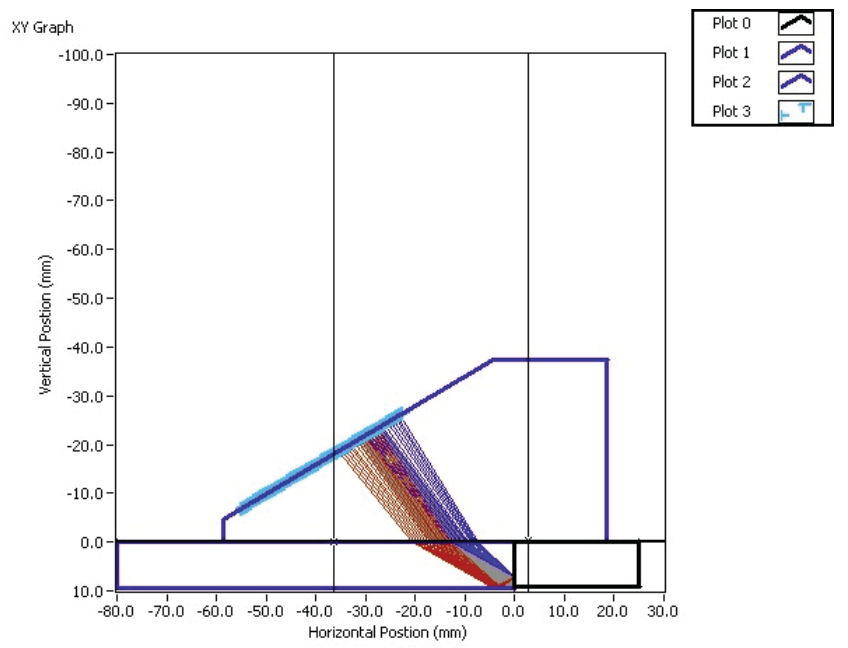

FIGURE 3. Phased-array focal law generation illustration of one target location on the root faces of the weld geometry. The illustration shows the path of sound from the individual elements of the used in send (upper direct focal lines-shown in blue on the CD distribution of the paper) and receive (lower with bounce off lower surface - shown in red on the CD distribution of the paper) apertures. Delays are calculated based on the expected time of flight on these paths to created constructive interference at the target point.

\section{PRELIMINARY RESULTS}

\section{Eddy Current Modeling}

The first step in the modeling was to generate the reference signals. Two types of off-the-shelf transmitreceive sensors were modeled - for surface and subsurface flaws. The reference surface flaw signals were obtained using frequencies of $100 \mathrm{kHz}$ and $400 \mathrm{kHz}$ from a $0.508 \times 7.11 \times 0.102 \mathrm{~mm}(0.02 \times 0.28 \times 0.004-\mathrm{in}$.) discontinuity. The signals from a subsurface discontinuity $2.03 \times 13.7 \times 0.102 \mathrm{~mm}(0.08 \times 0.54 \times 0.004$-in. $)$ under $6.35 \mathrm{~mm}(0.25$-in.) plate were modeled at $800 \mathrm{~Hz}$. The material of the specimens was $316 \mathrm{~L}$ similar to HLGMAW welded plates. The agreement between the modeled and the actual signals acquired with the modeled off-the-shelf sensors and specimens was good.

Two transmitter shapes were selected to investigate the depth of penetration versus transmitter size of 38.1 $\mathrm{mm}(1.5$-in.) to $102 \mathrm{~mm}$ (4-in.) and frequency of $100 \mathrm{~Hz}$ to $50 \mathrm{kHz}$. The data indicated that good penetration of $\sim 14$ $\mathrm{mm}(0.55$-in.) can be achieved with one of the transmitter shapes and frequencies of $500 \mathrm{~Hz}$.

For the selected transmitter, all three components $\Delta \mathrm{Bx}, \Delta \mathrm{By}$ and $\Delta \mathrm{Bz}$ of the magnetic field disturbed by planar flaws through the weld CL were modeled. Two of the components most sensitive to the flaw presence were selected to build the receiver components of the sensor.
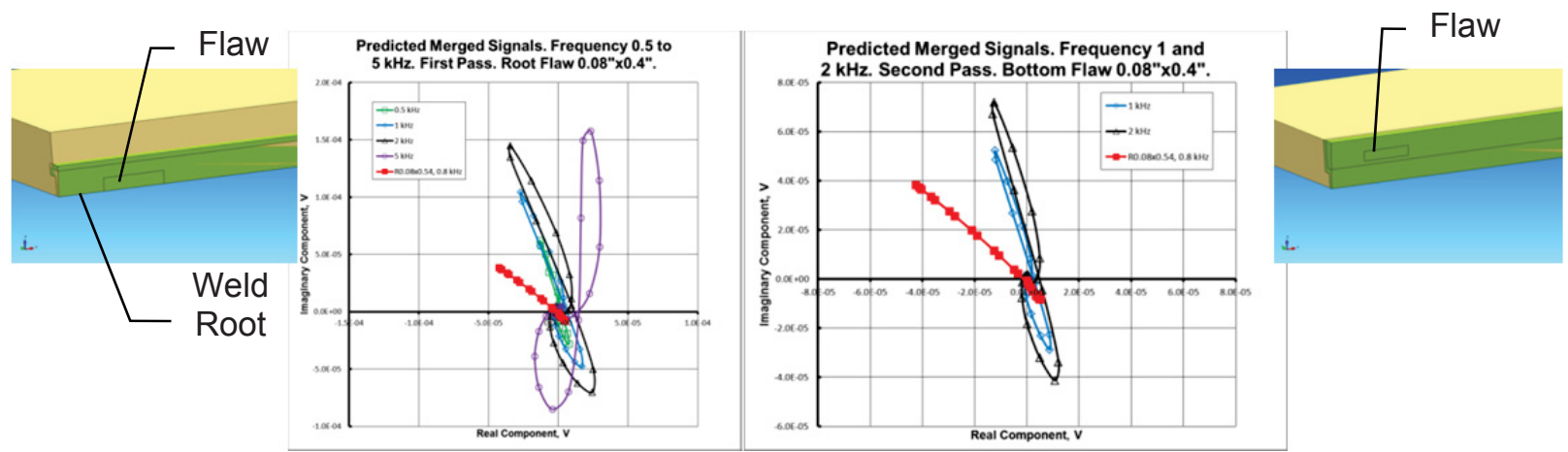
FIGURE 4. Signals from a planar flaw $2.03 \times 10.2 \mathrm{~mm}(0.08 \times 0.4-i n$.$) at the weld root after first pass (left) and at the bottom of$ the second pass or weld mid-wall (right) at various frequencies. Reference signal shown with square markers (in red color in CD distribution of this paper).

Following the selection of sensor transmitter and receiver components, the flaw interaction modeling started with the subsurface flaws because these flaws would be the most difficult to detect with ET. The electrical conductivity and magnetic permeability of the weld material (magnetic) were measured and used in the models to improve the modeling predictions accuracy. The results for a subsurface planar flaw in the root of the first pass and at the bottom of the second pass (mid-wall) are shown in FIGURE 4. The models predicted that a subsurface planar flaw $2.03 \times 10.2 \mathrm{~mm}(0.08 \times 0.4$-in.) might be detectable when compared to the reference (red).

\section{Root Face: Phased Array Ultrasonics}

A bench top scan of the weld shown in FIGURE 2 using the technique described in the approach section was completed. Tomoview is used as the display as shown in an annotated screen capture in FIGURE 5. A scan was completed with a linear slide with a constant acquisition rate to give a scan direction sample every millimeter. The larger, upper right window shows the data from one focal law directed at the vertical fusion boundary about mid height (time of flight on the vertical axis, scan position on the horizontal axis and amplitude represented with the color palette. The left pane represents all of the focal laws from top to bottom of the fusion surface at one scan location (depth on the vertical axis and time of flight on the horizontal axis). An important note is that the overall delay on the each focal law is adjusted to show a reflection from the fusion boundary on the nominal sound path for that target at the same time. This is an adjustment that makes a return from an unfused portion of the weld appear vertical in this view. As in [4], the vertical location and height of defects can be ascertained. Sound returned outside the nominal round trip time of flight is not readily interpreted, as it has travelled on sound paths other than the designed sound path.

In FIGURE 5, indications are shown in the scan plot correlate with the weld. Portions welded without laser reveal no fusion. A burn thru section where the laser was caused to dwell was apparent. Also, starts and stops and finally the unwelded portion of the block at the end showed the expected response. Portions of the weld where the weld pool drained through the laser weld did show up as an artifact at a time greater than the expected time of flight. This could be used as a redundant indicator of a weld that is experiencing weld pool drain out issues. There is also a direct measurement of pool height through the voltage and power measurement of the GMAW systems. 


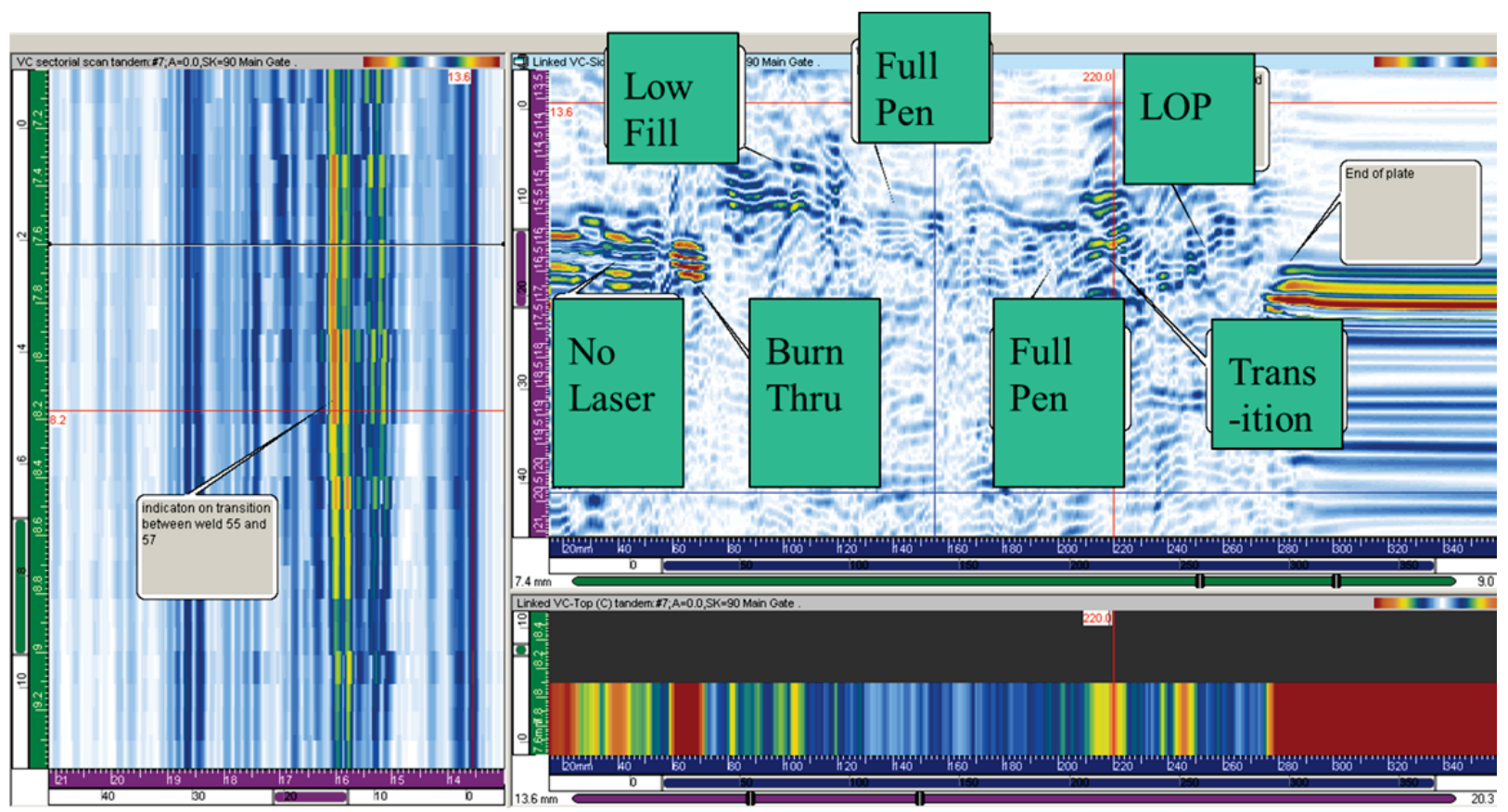

FIGURE 5. Phased-array focal law generation illustration of one target location on the root face of the weld geometry.

\section{CONCLUSION PATH FORWARD}

We provide a summary of path toward real-time diagnostics. Bench top feasibility and modeling studies show promise to achieve a diagnostic and possibly a feedback control mechanism in some instances. Eddy current and ultrasonic methods will be moved forward into the welding system with probe designs capable of working within the surface temperature envelope. This takes advantage of the localized heating and relatively cool surface temperatures near the welding laser and torch.

\section{Real Time Welding Diagnostics System}

The laboratory system used for these experiments will incorporate probes described here as well as other possible sensors. A primary weld parameter feedback mechanism of modifying the laser power is to be completed for the specific instance of achieving full penetration with minimal possibility of weld pool drain through using sensor readings from UT and possibly other systems. The system will be capable of undergoing a controlled shutdown should concrete indications be found from the sensor devices. The team comprised of the authors and their respective institutions continue to further the integration of the individual components towards methods and systems that are usable by industry.

\section{Eddy Current Modeling}

The following conclusions and recommendations can be made:

- An eddy current sensor concept for real or near-real time weld monitoring was investigated through computer modeling

- Preliminary modeling results indicated that subsurface flaws in the weld first and second passes might be detectable

Other flaw types (e.g. pores), sizes and locations through the weld thickness will be investigated as part of the first phase of the effort to finalize the sensor specifications 


\section{Root Face: Phased Array Ultrasonics}

This most critical aspect on the path forward for the UT sensor is the design of a probe that allows coupling without disrupting the weld process. This is a current area of focus of efforts.

Automatically interpreting the signatures from the UT system requires integration which has been achieved in other projects [5].

\section{ACKNOWLEDGMENTS}

We would like to thank Feng Yu and Dana Couch for their collaboration and insightful conversation on this project. The work described in this manuscript was supported by DOE NE Nuclear Energy Enabling Technology-Advanced Methods of Manufacturing and authored by a contractor of the U.S. Government under DOE-NE Idaho Operations Office Contract DE-AC07-05ID14517. Accordingly, the U.S. Government retains and the publisher, by accepting the article for publication, acknowledges that the U.S. Government retains a nonexclusive, paid-up, irrevocable, worldwide license to publish or reproduce the published form of this manuscript, or allow others to do so, for U.S. Government purposes.

\section{U.S. DEPARTMENT OF ENERGY DISCLAIMER}

This information was prepared as an account of work sponsored by an agency of the U.S. Government. Neither the U.S. Government nor any agency thereof, nor any of their employees, makes any warranty, express or implied, or assumes any legal liability or responsibility for the accuracy, completeness, or usefulness of any information, apparatus, product, or process disclosed, or represents that its use would not infringe privately owned rights. References herein to any specific commercial product, process, or service by trade name, trademark, manufacturer, or otherwise, does not necessarily constitute or imply its endorsement, recommendation, or favoring by the U.S. Government or any agency thereof. The views and opinions of authors expressed herein do not necessarily state or reflect those of the U.S. Government or any agency thereof.

\section{REFERENCES}

1. S.E. Webster, et.al., "EUR 2386 Hyblas: Economical and Safe Laser Hybrid Welding of Structure Steel in Luxembourg: Office for Official Publications of the European Communities, pp. 118, 2009.

2. A. Fellman and E. M. Westin, "Fiber Laser Hybrid Welding of Stainless Steels," in ICALEO 2008 - 27th International Congress on Applications of Lasers and Electro-Optics, Congress Proceedings, pp. 545-553, (2008).

3. E. Todorov, B. Nagy, S. Lavesque, N. Ames, and J. Na, "Inspection of Laser Welds with Array Eddy Current Technique," in Review of Progress in Quantitative Nondestructive Evaluation, edited by D. O. Thompson and D. E. Chimenti,. Denver, Colorado, pp. 1065-1072, July 15-20, 2012.

4. T. R. McJunkin, J.M. Davis, D.C. Kunerth, and A.D. Watkins, "Ultrasonic phased array implementation of the inside creeping wave sizing methodology," in 5th International Conference on NDE in Relation to Structural Integrity for Nuclear and Pressurized Components, San Diego, California, pp. 929-942, May 2006.

5. T. R. McJunkin and M. Manic, "Evolutionary adaptive discovery of phased array sensor signal identification," in 4th International Conference on Human System Interactions (HSI), pp 229-236, May 2011. [Online]. Available: http://dx.doi.org/10.1109/HSI.2011.5937371 